\title{
The Impact of Modifying Interpretive Bias on Contamination-Related Obsessive-Compulsive Symptoms
}

\author{
Shiu F. Wong ${ }^{1}\left[\right.$ ] Angela Scharfenberg ${ }^{2} \cdot$ Sandra Krause $^{3} \cdot$ Jessica R. Grisham $^{2}$
}

Accepted: 20 January 2022 / Published online: 9 February 2022

(c) The Author(s) 2022

\begin{abstract}
Cognitive-behavioural models of obsessive-compulsive disorder (OCD) propose that a tendency to negatively interpret ambiguous thoughts and situations plays a key role in maintaining the disorder. Moreover, some researchers have proposed that negative interpretive biases may share a common processing mechanism with attentional biases, with changes in one predicted to lead to changes in the other. The current study examined whether training positive (i.e., adaptive) interpretive bias of contamination-related OCD concerns using a cognitive bias modification paradigm (CBM-I) would lead to reductions in contamination concerns, as well as changes in contamination-related attentional bias. Undergraduate students with high levels of contamination-related OCD symptoms were randomly assigned to receive either positive $(n=31)$ or neutral $(n=33)$ CBM-I training. Participants in the positive training condition, relative to the neutral training condition, showed a significantly greater increase in positive interpretive bias, significantly less within-session behavioural avoidance of contaminants, and significantly reduced contamination-related cognitions (at one-week follow-up). Contrary to expectations, CBM-I training did not differentially impact attentional bias nor self-reported contamination-related OCD symptoms. We discuss future directions in applying CBM-I to contamination-related OCD.
\end{abstract}

Keywords Obsessive-Compulsive Disorder · Contamination · Cognitive-Bias Modification · Interpretation Bias

Obsessive-compulsive disorder (OCD) is characterised by the presence of recurrent and persistent thoughts, images, or impulses (obsessions) and/or time-consuming mental or behavioural acts that aim to resolve the obsessional fear (compulsions; American Psychiatric Association, 2013).

\section{Highlights}

- CBM-I used to train positive interpretive bias for contamination-related concerns

- Positive training, relative to neutral, increased adaptive interpretive bias

- Positive training, relative to neutral, was associated with less avoidance of contaminants

- Positive training did not result in adaptive shifts in attentional bias

Shiu F. Wong

Kelvin.Wong@latrobe.edu.au

1 Department of Psychology, Counselling, and Therapy, La Trobe University, Bundoora, Australia

2 School of Psychology, University of New South Wales, Kensington, Australia

3 Department of Psychology, Concordia University, Montreal, Canada
Contamination-related obsessions (e.g., recurring thoughts about being covered in germs) and compulsions (e.g., repetitive handwashing) are among the most common symptoms of OCD, with approximately $36 \%$ of OCD individuals reporting some form of contamination-related symptomatology (Coughtrey et al., 2012).

According to traditional cognitive-behavioural models of OCD, universally-experienced intrusions (Rachman \& de Silva, 1978; Radomsky et al., 2014) including those about contamination, take on obsessional qualities (i.e., increased frequency and distress) when an individual misattributes heightened significance towards the intrusion (Rachman, 1997, 1998; Salkovskis, 1985, 1989). That is, the individual may overestimate the likelihood of being contaminated and believe that they are solely responsible for preventing the spread of dangerous germs. They might then engage in compulsive washing behaviours to provide relief and prevent the feared consequences of contamination (e.g., sickness). This subsequent decrease in distress and the absence of feared outcomes results in a failure to disconfirm this misattribution of significance and negatively reinforces the washing compulsions and the OCD cycle. These models emphasise the 
centrality of these misattributions, or higher-order beliefs and cognitions, in the development and maintenance of OCD and are thus targeted for modification in cognitive-behavioural therapy.

A number of studies have reported a relation between OCD symptoms and the key belief domains identified by the Obsessive Compulsive Cognitions Working Group (2001, 2005): inflated responsibility for causing or preventing harm to the self or others, overestimation of threat, importance of and need to control thoughts, and perfectionism and intolerance of uncertainty (e.g., Frost \& Steketee, 1997; Purdon et al., 2005; Salkovskis et al., 1999; Tolin et al., 2003). A more recent study showed that, after controlling for selfreported symptoms of depression and anxiety, OCD patients endorsed more of these beliefs than healthy controls, and these beliefs were positively correlated with OCD symptoms (Tümkaya et al., 2015). However, research supporting the role of these beliefs in OCD has received criticism for being largely correlational (Abramowitz et al., 2007), with some critics going further as to doubting whether this research has brought about substantial improvements to treating OCD (Cougle \& Lee, 2014). Accordingly, there is a need for more experimental paradigms (e.g., Arntz et al., 2007; Reeves et al., 2010; Wong et al., 2021b) to clarify the validity of these cognitive-behavioural models of OCD.

One such experimental paradigm is cognitive bias modification for interpretation bias (CBM-I), which aims to directly target specific interpretive biases, including misappraisals of significance (Beadel et al., 2014; Williams \& Grisham, 2013). CBM-I generally involves repeatedly presenting participants with solutions to ambiguous scenarios in a benign manner to discourage maladaptive and promote adaptive interpretations of the stimuli. The most widely used method for CBM-I is the three-sentence protocol pioneered by Mathews and Mackintosh (2000). The first sentence of each scenario sets the context (e.g., "Your friend comes over to visit with their toddler"), whilst the second sentence contains ambiguous content about a potential threat ("As she changes the child's nappy, she places the used baby wipes in a ag before putting them in the bin"). The third sentence resolves the ambiguity of the scenario and participants are required to complete a missing word fragment to ensure their active engagement with this resolution ("The likelihood of her spreading bacteria is $l \_w$ ").

CBM-I has seen increasing application in experimental investigations of the proposed causal relation between misappraisals of significance and OCD symptoms. Relative to control training, which differs by study, CBM-I is able to reduce responsibility beliefs (Grisham et al., 2014), beliefs about the importance of and need to control thoughts (Clerkin et al., 2014; Stech \& Grisham, 2017), negative beliefs about memory and uncertainty (Black \& Grisham, 2018), and perfectionism (Wong et al., 2021b). Unfortunately, CBM-I's clinical application in OCD is currently limited partly because these studies have reported mixed findings regarding its impact on symptom reduction and behaviour. Two studies examining the effectiveness of CBM-I specifically in individuals with heightened contamination concerns have similarly reported mixed results (Beadel et al., 2016; Conley \& Wu, 2018). These studies matched the CBM-I training material to the target population and showed that this significantly reduced contamination-related interpretive bias, relative to control training (Beadel et al., 2016; Conley \& Wu, 2018) and when the training material was not related to contamination concerns (i.e., acrophobia; Beadel et al., 2016). However, only Conley and $\mathrm{Wu}$ (2018) showed that CBM-I was associated with less behavioural avoidance of contaminants on their behavioural approach task. Study-specific limitations notwithstanding, both studies support the idea that CBM-I is more likely to be effective in shifting interpretive biases, symptoms and/or behaviour if the training target and population align.

Other cognitive-behavioural models of OCD emphasise the role of more implicit information processing methods (Williams et al., 1997), such as attention and inhibition, in maintaining OCD. Specifically, these models suggest that individuals with OCD selectively attend to or fail to inhibit the processing of threatening information in their environment, particularly stimuli related to their primary OCD symptom domain (e.g., contaminants or intrusive thoughts about being contaminated). Indeed, patients with contamination-related OCD display attentional bias towards contamination-relevant items (Foa et al., 1993; Tata et al., 1996) as well as deficits in their ability to inhibit the processing of irrelevant information (Maltby \& Tolin, 2003). These models argue that these biases in information processing exaggerate the presence and even the importance of threatening stimuli, which may contribute to the development and maintenance of OCD.

Although both models of OCD discussed above emphasise different cognitive processes, it is likely that they stem from a shared processing mechanism and interact to maintain this disorder. For example, if one misinterprets their intrusions about being contaminated with germs to be indicative of a real threat, then they might start attending more to these intrusions and their triggers, such as potential contaminants in the environment ("My intrusions are important, therefore I should be vigilant"). On the other hand, one might be more likely to misattribute the significance of intrusions and other threatening stimuli because they selectively process this information ("I am vigilant because my intrusions are important"). Even though this interaction between interpretive and attentional biases seems intuitive, only a few studies have examined this relation in the context of anxiety. In a community sample of socially anxious individuals, those who received training to make benign interpretations of ambiguous social scenarios, relative to 
control training, demonstrated better disengagement from threatening stimuli during an attention task (Amir et al., 2010). Conversely, in a sample of young females with normal levels of trait anxiety, those who received training to attend to threat were more likely than those who received the control training to interpret ambiguous information in a threat-related manner (White et al., 2011). Despite growing studies targeting interpretive and attentional biases in OCD, there is currently no research on the impact of targeting interpretive bias (using techniques such as CBM-I) on attentional bias in OCD.

\section{Aims and Hypotheses}

The current study aimed to examine the effect of CBM-I on reducing contamination-related OCD symptoms and attentional bias in a sample with elevated contamination concerns. We first hypothesised that participants who received CBM-I training to promote adaptive interpretations of ambiguous contamination-related situations (positive training), relative to a neutral training, would evidence a greater increase in adaptive interpretive bias and be less avoidant of contaminants on a series of behavioural approach tasks. We further hypothesised that the positive training condition, relative to the neutral training condition, would demonstrate a greater decrease in self-reported symptoms of contaminationrelated OCD and contamination-related cognitions at one-week following the training. Finally, we hypothesised that the positive training condition, relative to the neutral training condition, would be associated with a greater reduction in attentional bias for contamination-related stimuli.

\section{Method}

\section{Participants}

The current sample was recruited via the first-year undergraduate psychology research pool at the University of New South Wales. As per course requirements, all enrolled firstyear psychology students $(N=1,249)$ completed a battery of pre-screening measures, including the Padua Inventory - Washington State University Revision (PI-WSUR) contamination fear subscale (Burns et al., 1996). Individuals who met diagnostic criteria for OCD scored, on average, 13.87 on this subscale (Burns et al., 1996) and so, in accordance with this normative data and previous research (Armstrong et al., 2012), students who scored $\geq 13$ at the time of the pre-screen were classified as high contamination fear and were eligible to participate in the larger study $(N=280)$. The final sample of eligible participants who signed up and completed the larger study in exchange for course credit was composed of 68 individuals. Following random assignment to receive either positive or neutral training, there were 33 participants in the positive training condition and 35 participants in the neutral training condition. The mean age was 19.21 years $(S D=3.61)$ and participants identified either as Asian (54.41\%), Caucasian $(22.06 \%)$, or Aboriginal/Torres Strait Islander, African, and Other $(23.53 \%)$. Contamination symptoms on the PI-WSUR reported by the final sample (range $=4-36$, $M=16.16, S D=6.86$ ) were comparable to that of OCD samples reported in previous research (Burns et al., 1996).

\section{Tasks and Measures}

\section{Cognitive Bias Modification for Interpretation Bias (CBM-I) Training}

The CBM-I training used in this study aimed to promote adaptive interpretations of common scenarios specifically related to contamination. This task was programmed using the Inquisit software and was delivered on a standardised laboratory computer. Interpretive bias was modified using the threesentence protocol developed by Mathews and Mackintosh (2000) and described in the introduction. See Fig. 1 for a schematic representation of an example target training item. The positive condition always disambiguated scenarios in an adaptive way (i.e., inconsistent with a contamination-related interpretation), thereby establishing a learning contingency. In the neutral condition, however, half of the scenarios were resolved in an adaptive way and the other half were resolved in a maladaptive way (i.e., consistent with a contaminationrelated interpretation) so that no learning contingency was established. After disambiguating the scenario, participants were presented with a comprehension question, which served to ensure that participants had understood the scenarios and to reinforce the required interpretation of the ambiguous scenario. Thirty-two scenarios were each presented twice and in a random order. Scenarios were derived from training items developed by Whitton et al. (2013) as well as self-report measures of maladaptive contamination beliefs and symptoms, including the Obsessive Beliefs Questionnaire - 44 (Obsessive Compulsive Cognitions Working Group, 2005), Yale-Brown Obsessive-Compulsive Symptoms Checklist (Goodman et al., 1989), and the Obsessive Compulsive Inventory - Revised (Foa et al., 2002). Two unrelated practice scenarios were completed with the experimenter prior to the CBM-I training.

\section{Interpretation Bias Measure}

This task measured interpretive bias by assessing participants' interpretation of novel ambiguous information. Participants were presented with ten ambiguous scenario 


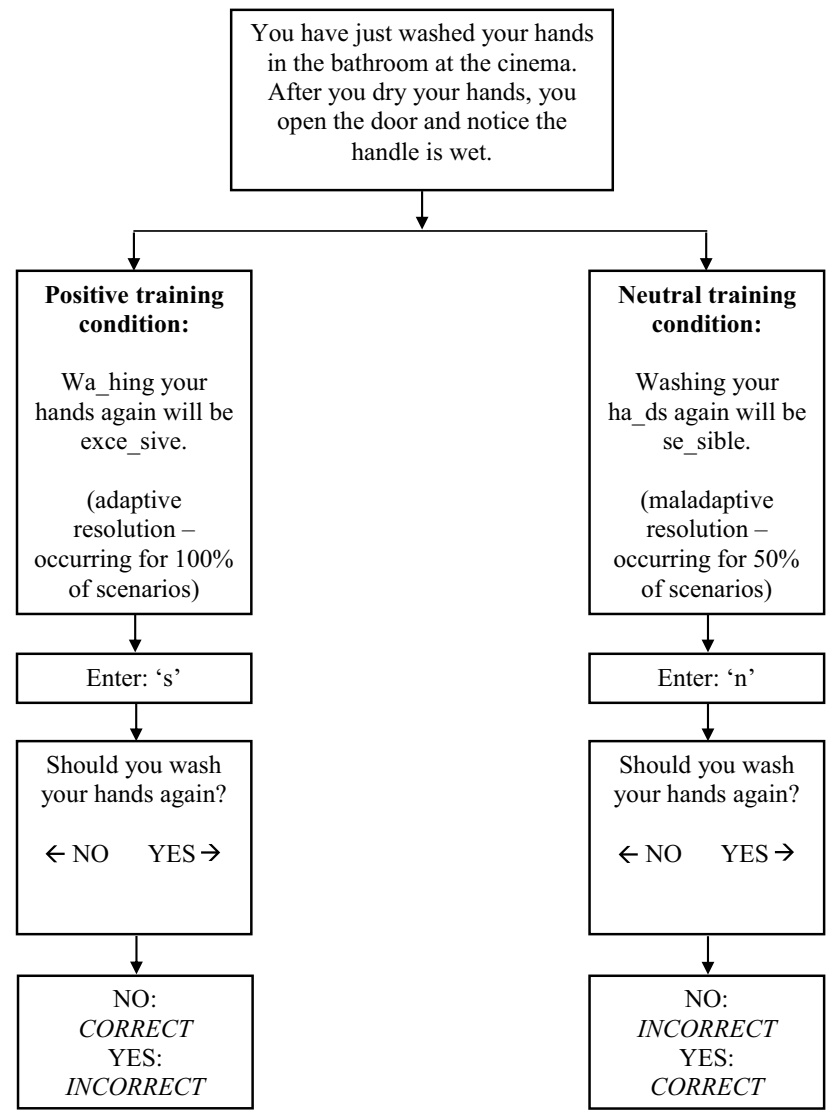

Fig. 1 Schematic representation of CBM-I training with a sample item

descriptions that were paired with a title. These scenarios were consistent with previous studies (Clerkin \& Teachman, 2011; Clerkin et al., 2014; Williams \& Grisham, 2013) and modified to contain content relevant to contamination concerns. To encourage engagement and check for understanding, participants were required to imagine themselves in the scenario and asked to rate how well they understood each scenario on a scale ranging from 1 (not well at all) to 9 (very well). This was followed by a neutral images filler task in which participants rated the pleasantness and vividness of a set of neutral images sourced from the International Affective Picture System (Lang et al., 2005). The purpose of the filler task was to control for memory effects by providing a short delay between the presentation of ambiguous scenarios and the next component of the interpretation bias measure: the recognition task.

In the recognition task, participants were presented with the titles of the ten ambiguous scenario descriptions but without the original descriptions. Instead, each title was now accompanied with four similar descriptions that reflected an adaptive contamination-related interpretation (positive target), a maladaptive contamination-related interpretation (negative target), an unrelated positive interpretation (positive foil), or an unrelated negative interpretation (negative foil). Participants were instructed to rate, using a 1- to 4-point scale, how similar the new scenarios were to the original scenario that went with the title $(1=$ very different in meaning and $4=$ very similar in meaning). Targets were included to verify whether the CBM-I training produced training-congruent changes in adaptive contaminationrelated interpretations. Target bias scores were calculated by subtracting the summed negative target score from the summed positive target score, with higher scores indicating that participants interpreted scenarios as benign or less threatening. Foil bias scores were created in the same manner (positive foil minus negative foil) and used to verify that the training induced changes in interpretive bias specific to contamination-related OCD rather than changes in overall valence. See Table 1 for an example of the interpretation bias measure.

\section{Attention Task}

Attention was measured using a protocol adapted from previous studies (Armstrong et al., 2012, 2013). Forty-eight images (originally taken from the International Affective Picture System and publicly available sources) were taken from Armstrong et al. (2012), and included 12 pictures from each of the following categories: contamination-related threat (e.g., bodily excretions and waste), general threat (e.g., guns, knives, and physical assault), appetitive (e.g., animals and smiling people), and neutral (e.g., household objects). Images were sized to fit $10.82^{\circ} \times 8.26^{\circ}$ and presented in $2 \times 2$ arrays comprised of one image from each category. The images were presented on a grey background, with their innermost corners $1.34^{\circ}$ from the central fixation point, and their centres $8.2^{\circ}$ from the central fixation point. Stimulus arrays were presented on a 23 -inch monitor $(1920 \times 1080$ resolution, $60 \mathrm{~Hz}$ ). The task was conducted using a Tobii TX300 eye tracker, a video-based eye-tracker with bright and dark pupil tracking methods, and Tobii Studio software (version 3.3.0; Tobii Technology, Danderyd, Sweden). A sampling rate of $60 \mathrm{~Hz}$ was used, and a spatial resolution of $0.04^{\circ}-0.05^{\circ}$. Participants were seated in front of the computer screen and the Tobii Studio software displayed the distance between their eyes and the screen; participants were positioned so that they were $64 \mathrm{~cm}$ from the screen, in accordance with the Tobii operating manual.

Prior to the commencement of the task, a 9-point calibration procedure was completed, in accordance with the operating manual. Participants were asked to focus on a red dot that appeared on the screen and follow it with their eyes as it moved across the screen. Following successful calibration, participants were provided with the following instructions both verbally and as text: 
Table 1 Example from the Interpretation Bias Measure

\begin{tabular}{|c|c|}
\hline Section & Example \\
\hline \multicolumn{2}{|l|}{ Ambiguous scenario } \\
\hline Title & THE PARK \\
\hline Ambiguous description (original) & $\begin{array}{l}\text { You are at the park and need to use the toilet. As you enter the public toilets, you notice that the ground is } \\
\text { wet. You walk into the cubicle closest to you }\end{array}$ \\
\hline \multicolumn{2}{|l|}{ Neutral images filler task } \\
\hline \multicolumn{2}{|l|}{ Recognition task } \\
\hline Title & THE PARK \\
\hline Positive target & $\begin{array}{l}\text { You are at the park and need to use the toilet. As you enter the public toilets, you notice that the ground is } \\
\text { wet. You think to yourself that the liquid is probably water }\end{array}$ \\
\hline Negative target & $\begin{array}{l}\text { You are at the park and need to use the toilet. As you enter the public toilets, you notice that the ground is } \\
\text { wet. You think to yourself that the liquid is probably urine }\end{array}$ \\
\hline Positive foil & $\begin{array}{l}\text { You are at the park and need to use the toilet. As you enter the public toilets, you notice that the ground is } \\
\text { wet. You are glad you got some fresh air today }\end{array}$ \\
\hline Negative foil & $\begin{array}{l}\text { You are at the park and need to use the toilet. As you enter the public toilets, you notice that the ground is } \\
\text { wet. You think to yourself that the cleaners are lazy }\end{array}$ \\
\hline
\end{tabular}

During the recognition task, participants were asked to rate how similar or different each scenario description was to the original: from $1=v e r y$ different in meaning to $4=$ very similar in meaning. Ratings were summed to create an overall score for each of the four categories

\begin{abstract}
"During this task, a series of images will be presented on the screen. Please view the images as you like, but do not look away from the monitor. Between each set of images, a cross will appear in the centre of the screen; please focus on this when it appears, and then view the images as you please. You do not have to press anything during the task; the computer will automatically run through everything. Please remain as still as possible for the duration of the task."
\end{abstract}

Stimulus arrays were presented for $6 \mathrm{~s}$, followed by a $1 \mathrm{~s}$ inter-trial interval. The fixation cross was presented on the same grey background as the experimental trials and intertrial interval and appeared for $700 \mathrm{~ms}$ after the inter-trial interval, immediately prior to stimulus onset. See Fig. 2. Twelve stimulus arrays were presented sequentially. Image location was balanced across image type - each image type appeared in each corner location three times in total during the attention task. Finally, the attention task was administered twice: before and after the CBM-I training. During the second administration, the set of images presented in each stimulus array was identical to the first administration, but image location was altered so that no image appeared in the same location twice and location was balanced across image type.

Eye movement data reduction Eye movement events were defined using the Tobii Studio software. Areas of interest were defined as rectangles containing each image, as well as a rectangle with $1.93^{\circ} \times 1.85^{\circ}$ diameter at the location of the fixation target (central region). Trials were excluded from initial fixation analyses if gaze was not directed at the central region at stimulus onset. For each participant, orienting of gaze was assessed by computing the number of trials in which the image type of interest captured the initial fixation, divided by the total number of valid trials. Fixation duration was assessed by calculating the time spent viewing each image type per trial and averaging across trials (Armstrong et al., 2012).

\section{Padua Inventory - Washington State University Revision (PI-WSUR; Burns et al., 1996), Contamination Fear Subscale}

The PI-WSUR contamination fear subscale is a 10 -item self-report measure of contamination-related obsessions and washing compulsions (e.g., 'I avoid using public toilets because I am afraid of disease and contamination'). Items are scored on a 0 - to 4 -point scale $(0=$ not at all and $4=$ very much). According to Burns et al. (1996), the PI-WSUR contamination fear subscale has good test-retest reliability $(r=0.72)$ and internal consistency (Cronbach's $\alpha=0.85)$.

\section{Contamination Cognitions Scale (CCS; Deacon \& Olatunji, 2007)}

The CCS is a 13-item self-report measure of the tendency to overestimate the likelihood and severity of contamination. Participants are presented with a list of 13 items often associated with germs (e.g., door handles, toilet seats, elevator buttons) and asked to imagine what would happen if they touched the item and were unable to wash their hands afterwards. Participants then provide two ratings for each item: the likelihood of contamination if they touched the item, and 


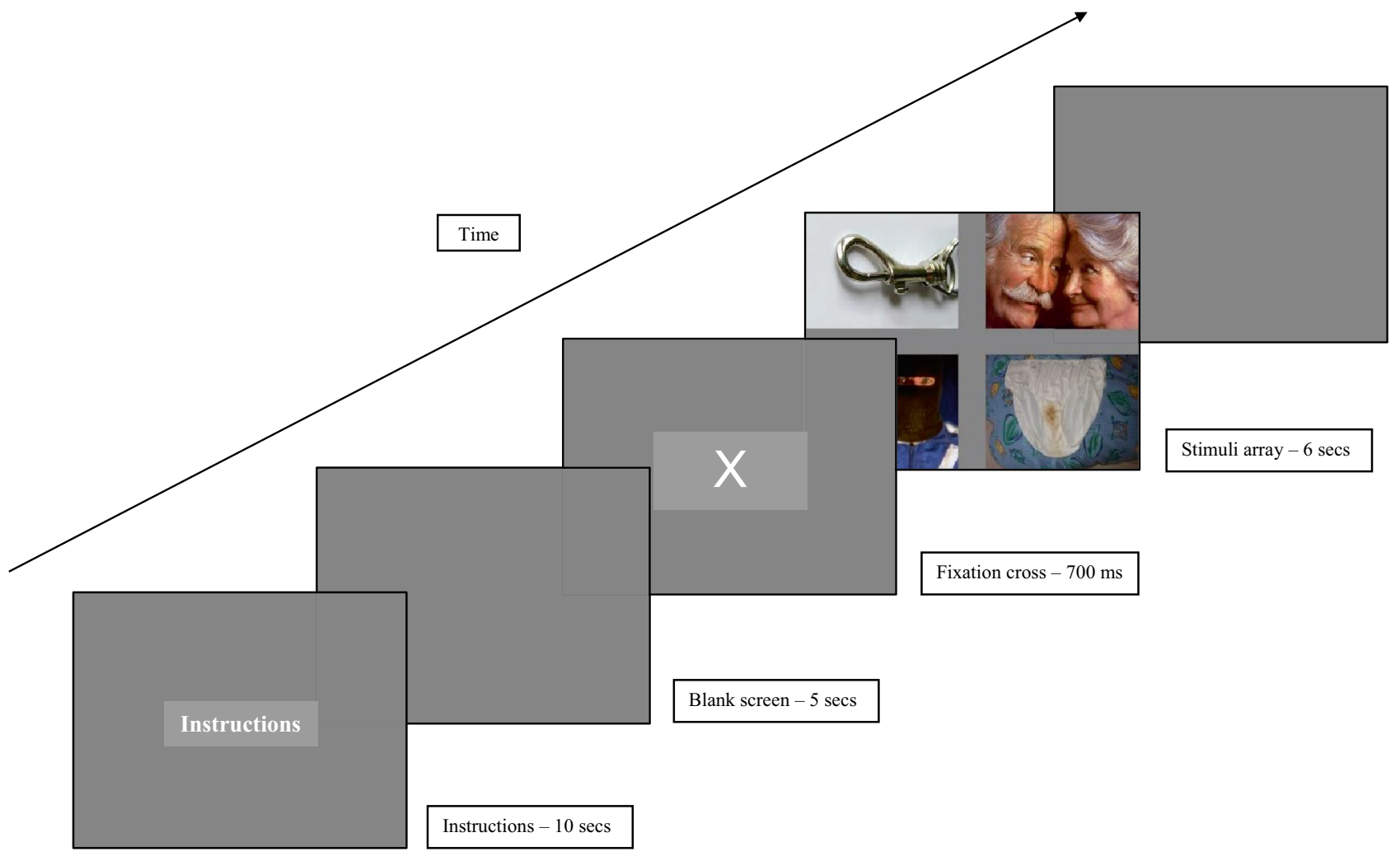

Fig. 2 Stimuli array presentation and timing during the attention task

how severe the consequences would be if they were actually contaminated. Ratings are provided on two 0 - to 100-point scales (likelihood: $0=$ not at all likely and $100=$ extremely likely; severity: $0=$ not at all bad and $100=$ extremely bad). Likelihood and severity ratings averaged across the 13 items are added together to form the total CCS score. According to Deacon and Olatunji (2007), the CCS has high test-retest reliability $(r=0.94)$ and internal consistency (Cronbach's $\alpha=0.97)$.

\section{Behavioural Approach Tasks (BATs)}

Three BATs were adapted from previous studies and used to assess differences in behavioural approach and responding towards contamination-related stimuli (Cougle et al., 2007; Deacon \& Olatunji, 2007; Najmi et al., 2012; Whitton et al., 2013). Each BAT involved a hierarchy of six increasingly difficult steps of approach towards an item: touch the item with 1) a sheet of tissue, 2) a finger, 3) one hand, 4) both hands, 5) touch the item and then touch one's arms and chest, and 6) touch the item and then touch one's face. If participants were able to complete the first step, the experimenter asked them to complete the next step on the hierarchy until they reached the last step or refused to perform a step, at which point they moved onto the next BAT. Immediately following successful completion of a step on the hierarchy, participants rated their peak anxiety and disgust on a scale from 0 (not anxious/disgusted) to 100 (extremely anxious/ disgusted).

The first BAT involved approaching a pile of underwear and clothes, with participants being told, "This is a pile of used clothes". The second BAT involved approaching a mixture of dirt, dead cockroaches, and human hair, with participants being told, "This is a mixture of dirt, dead insects, and hair". The final BAT involved approaching a bed pan, which was made to look unclean with garden soil and water, with participants being told, "This is a bedpan". When participants were finished interacting with each item, the experimenter gave them an antiseptic wipe and instructed them to wipe their hands for up to $10 \mathrm{~s}$ in order to minimise carry-over effects between items, as per Cougle and colleagues' (2007) recommendation. Previous research on the psychometric properties of these BATs suggests that they are best used as a combined measure (Najmi et al., 2012). Therefore, a composite behavioural approach score was calculated by adding the number of steps completed on each BAT (maximum of 18), with higher scores indicating less contamination-related avoidance. Composite anxiety and disgust scores were calculated by respectively adding anxiety and disgust ratings of completed steps on the BATs. 
Session 1 (Day 1):

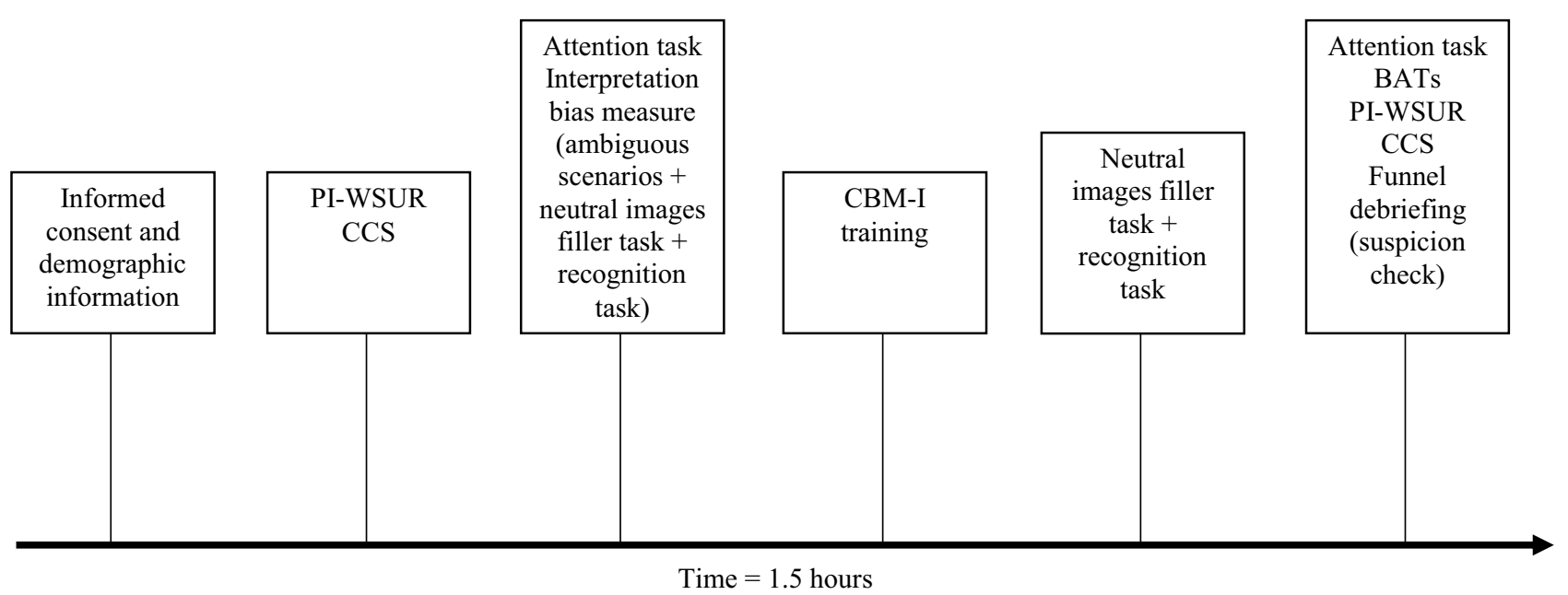

Session 2 (Day 8):

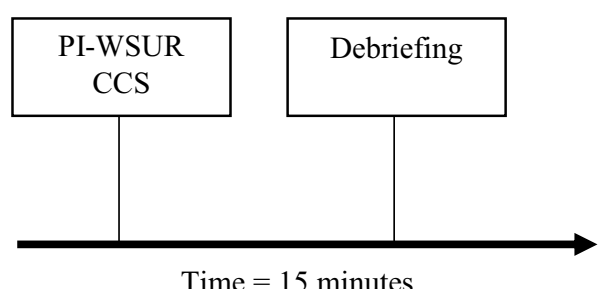

Fig. 3 Experiment timeline

\section{Procedure}

During the experimental session, participants first provided their written consent and demographic information, and then completed computerised versions of the PI-WSUR contamination fear subscale and the CCS. Participants then completed the first attention task and the interpretation bias measure (ambiguous scenarios, neutral images filler task, and recognition task), before being randomly assigned to the positive or neutral training condition. Training was followed by the second neutral images filler task and recognition task. Finally, participants completed the second attention task, the BATs, the PI-WSUR contamination fear subscale, and the CCS. At this point the experimenter conducted a partial funnel debriefing procedure to ascertain any suspicions participants had regarding the true purpose of the study.

One-week following the experimental session, participants were emailed a link to complete, within $48 \mathrm{~h}$, the PIWSUR contamination fear subscale and CCS. Upon completion, participants were emailed the full study debrief and credited for their participation. See Fig. 3 for the experiment timeline.

\section{Results \\ Condition Differences on Demographics and Pre-training Measures}

Potential outliers were screened for by conducting a visual check of histograms, normal probability plots, and box plots. Four statistical outliers for target bias scores on the recognition task (2 participants from each condition) were detected and removed from subsequent analyses. ${ }^{1}$

An independent samples t-test revealed that mean age did not differ significantly between conditions, $t(62)=0.01, p=0.99$, Cohen's $d=0.005$. A chi-square

\footnotetext{
$\overline{1}$ In addition, some participants who initially scored above the clinical cut-off on the PI-WSUR during the pre-screen no longer scored above this cut-off when they presented for the experimental session (positive condition: $n=9$; neutral condition: $n=14$ ). Analyses conducted with participants who only scored above the cut-off at the experimental session revealed a similar pattern of results as the full sample. Given this and that fluctuation in scores on these self-report measures reflects the clinical reality of OCD symptoms, we report results based on the full sample.
} 
Table 2 Demographics and Main Outcome Variables (Minus BATs) Across Each Assessment Timepoint

\begin{tabular}{|c|c|c|c|c|c|c|}
\hline & \multicolumn{3}{|l|}{$\begin{array}{l}\text { Positive condition } \\
(n=31)\end{array}$} & \multicolumn{3}{|l|}{$\begin{array}{l}\text { Neutral condition } \\
(n=33)\end{array}$} \\
\hline & $\begin{array}{l}\text { Pre-training } \\
M(S D)\end{array}$ & $\begin{array}{l}\text { Post-training } \\
M(S D)\end{array}$ & $\begin{array}{l}\text { Follow-up } \\
M(S D)\end{array}$ & $\begin{array}{l}\text { Pre-training } \\
M(S D)\end{array}$ & $\begin{array}{l}\text { Post-training } \\
M(S D)\end{array}$ & $\begin{array}{l}\text { Follow-up } \\
M(S D)\end{array}$ \\
\hline Gender & $64.5 \%$ female & & & $73.7 \%$ female & & \\
\hline Age & 18.87 years $(2.35)$ & & & 18.88 years $(2.03)$ & & \\
\hline \multicolumn{7}{|c|}{ Self-report measures } \\
\hline PI-WSUR & $\begin{array}{l}16.03 \\
(6.48)\end{array}$ & $\begin{array}{l}18.26 \\
(7.37)\end{array}$ & $\begin{array}{l}16.94 \\
(7.04)\end{array}$ & $\begin{array}{l}15.87 \\
(6.54)\end{array}$ & $\begin{array}{l}18.52 \\
(8.71)\end{array}$ & $\begin{array}{l}18.65 \\
(8.15)\end{array}$ \\
\hline CCS & $\begin{array}{c}53.60 \\
(16.27)\end{array}$ & $\begin{array}{c}55.37 \\
(17.23)\end{array}$ & $\begin{array}{c}51.51 \\
(18.49)\end{array}$ & $\begin{array}{c}59.04 \\
(23.03)\end{array}$ & $\begin{array}{c}61.08 \\
(22.90)\end{array}$ & $\begin{array}{c}61.77 \\
(23.54)\end{array}$ \\
\hline \multicolumn{7}{|l|}{ Recognition task } \\
\hline Target bias & $\begin{array}{c}3.19 \\
(3.54)\end{array}$ & $\begin{array}{c}6.65 \\
(4.32)\end{array}$ & & $\begin{array}{c}5.03 \\
(5.26)\end{array}$ & $\begin{array}{c}6.15 \\
(6.56)\end{array}$ & \\
\hline Foil bias & $\begin{array}{c}6.03 \\
(5.47)\end{array}$ & $\begin{array}{c}8.39 \\
(6.32)\end{array}$ & & $\begin{array}{c}6.03 \\
(6.04)\end{array}$ & $\begin{array}{c}9.09 \\
(7.16)\end{array}$ & \\
\hline \multicolumn{7}{|l|}{ Orienting of gaze } \\
\hline Contamination & $\begin{array}{c}.19 \\
(.18)\end{array}$ & $\begin{array}{c}.23 \\
(.15)\end{array}$ & & $\begin{array}{c}.19 \\
(.19)\end{array}$ & $\begin{array}{c}.18 \\
(.12)\end{array}$ & \\
\hline Threat & $\begin{array}{c}.22 \\
(.17)\end{array}$ & $\begin{array}{c}.26 \\
(.17)\end{array}$ & & $\begin{array}{c}.23 \\
(.16)\end{array}$ & $\begin{array}{c}.29 \\
(.15)\end{array}$ & \\
\hline Neutral & $\begin{array}{l}.15 \\
(.15)\end{array}$ & $\begin{array}{c}.16 \\
(.12)\end{array}$ & & $\begin{array}{c}.18 \\
(.14)\end{array}$ & $\begin{array}{c}.17 \\
(.20)\end{array}$ & \\
\hline Appetitive & $\begin{array}{c}.41 \\
(.26)\end{array}$ & $\begin{array}{c}.36 \\
(.18)\end{array}$ & & $\begin{array}{c}.37 \\
(.17)\end{array}$ & $\begin{array}{c}.36 \\
(.17)\end{array}$ & \\
\hline Fixation duratio & & & & & & \\
\hline Contamination & $\begin{array}{l}1.11 \\
(.28)\end{array}$ & $\begin{array}{c}.91 \\
(.36)\end{array}$ & & $\begin{array}{l}1.12 \\
(.32)\end{array}$ & $\begin{array}{c}.94 \\
(.38)\end{array}$ & \\
\hline Threat & $\begin{array}{l}1.12 \\
(.26)\end{array}$ & $\begin{array}{l}1.10 \\
(.41)\end{array}$ & & $\begin{array}{l}1.23 \\
(.30)\end{array}$ & $\begin{array}{l}1.25 \\
(.49)\end{array}$ & \\
\hline Neutral & $\begin{array}{l}1.05 \\
(.20)\end{array}$ & $\begin{array}{l}1.09 \\
(.42)\end{array}$ & & $\begin{array}{l}1.07 \\
(.24)\end{array}$ & $\begin{array}{l}1.04 \\
(.35)\end{array}$ & \\
\hline Appetitive & $\begin{array}{l}1.47 \\
(.50)\end{array}$ & $\begin{array}{l}1.80 \\
(.80)\end{array}$ & & $\begin{array}{l}1.52 \\
(.48)\end{array}$ & $\begin{array}{l}1.82 \\
(.58)\end{array}$ & \\
\hline
\end{tabular}

PI-WSUR Padua Inventory Washington State University Revision - Contamination Fear Subscale, CCS Contamination Cognitions Scale

test revealed no significant difference between conditions with respect to gender, $\chi^{2}(1,64)=0.50, p=0.48$, and ethnicity, $\chi^{2}(4,64)=4.47, p=0.35$. Independent samples t-tests revealed no significant differences between conditions on pre-training contamination-related OCD symptoms (PI-WSUR), $t(62)=-0.21, p=0.84$, Cohen's $d=0.05$, and contamination-related cognitions (CCS), $t(62)=0.87, p=0.39$, Cohen's $d=0.22$. See Table 2 for means and standard deviations for demographics and main outcome variables (minus BATs) across each assessment timepoint and separated by condition.

\section{Training-Related Changes in Interpretive Bias}

To confirm that the positive condition, relative to the neutral condition, exhibited a more adaptive interpretive bias of ambiguous, contamination-related scenarios following the training, a 2 (condition: positive vs. neutral) $\times 2$ (time: pre- vs. post-training) mixed model analysis of variance (ANOVA) was conducted, with condition as the betweensubjects variable; time as the within-subjects variable; and target bias scores on the recognition task as the dependent variable. There was a significant main effect of time, $F(1$, 
Fig. 4 Mean target bias scores for each training condition at pre-training and post-training. Positive scores indicate more adaptive interpretive bias of ambiguous, contaminationrelated scenarios. Error bars represent standard errors. Bottom bracket represents the positive condition. $* p<.05$

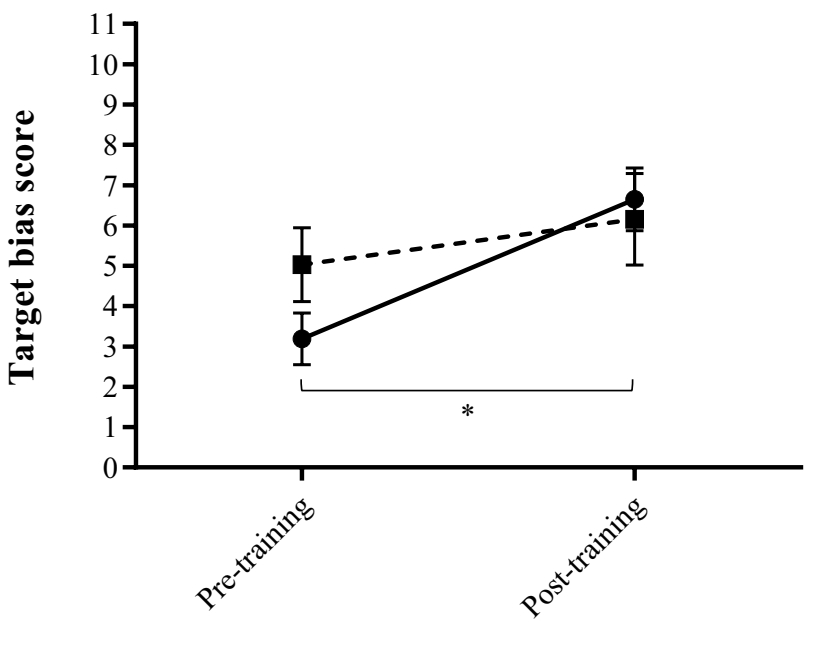

Time
$62)=17.52, p<0.001$, partial $\eta^{2}=0.22$, and, as expected, a significant interaction effect, $F(1,62)=4.55, p=0.04$, partial $\eta^{2}=0.07$. To understand the interaction effect, follow-up analyses using paired samples t-tests were conducted within each condition. We found that the positive condition significantly increased in mean target bias scores over time, $t(30)=-5.09, p<0.001$, Cohen's $d=-0.91$, and the neutral condition demonstrated no significant changes over time, $t(32)=-1.33, p=0.19$, Cohen's $d=-0.23$. See Fig. 4 .

To confirm that the positive training was specifically inducing an adaptive interpretive bias of ambiguous, contamination-related scenarios, rather than ambiguous, general scenarios, the same mixed model ANOVA was conducted but with foil bias scores on the recognition task as the dependent variable. Contrary to expectations, there was a significant main effect of time, $F(1,62)=20.28, p<0.001$, partial $\eta^{2}=0.25$, suggesting that participants in both conditions endorsed more positive interpretations over time.
As expected, the interaction effect was not significant, $F(1$, $62)=0.34, p=0.56$, partial $\eta^{2}=0.01$. See Fig. 5 .

\section{Training-Related Changes in Attentional Bias}

\section{Orienting of Gaze}

To test the hypothesis that positive, relative to neutral training would lead to a decrease in orienting bias (i.e., image-type that captures initial fixation following stimulus onset) towards contamination-related images, a 2 (condition: positive vs. neutral) $\times 2$ (time: pre- vs. post-training) mixed model multivariate analysis of variance (MANOVA) was conducted, with condition as the between-subjects variable; time as the within-subjects variable; and orienting bias scores for each of the four image types (contamination, threat, neutral, appetitive) as the dependent variables. For the overall mixed model MANOVA, there was
Fig. 5 Mean foil bias scores for each training condition at pre-training and post-training. Positive scores indicate more adaptive interpretive bias of ambiguous, general scenarios. Error bars represent standard errors

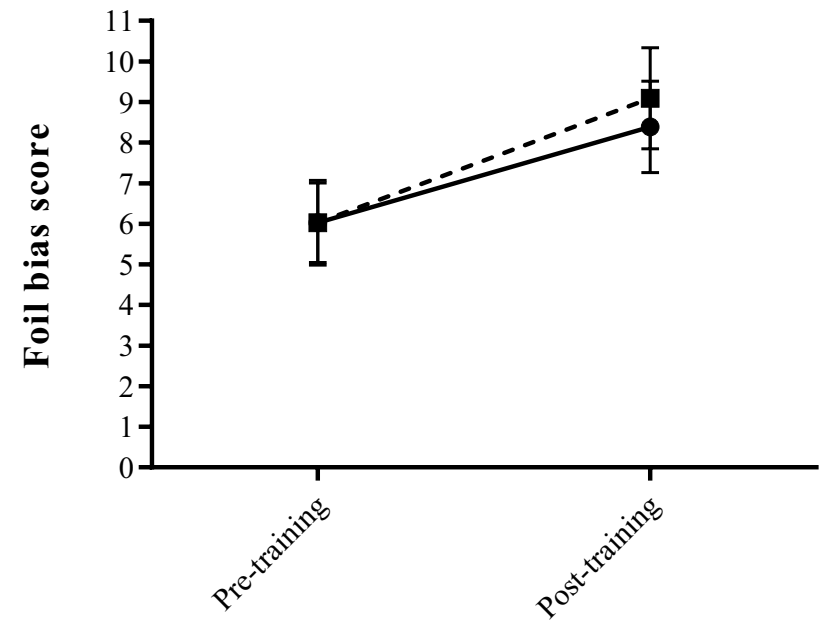

Time 
no significant main effect of time, $F(4,59)=1.38, p=0.25$, partial $\eta^{2}=0.09$, and no significant interaction effect, $F(4$, 59) $=0.31, p=0.87$, partial $\eta^{2}=0.02$. The latter indicates that conditions did not significantly differ in their pre- to post-training changes in orienting bias towards any of the images, including contamination-related images.

\section{Fixation Duration}

To test the hypothesis that positive, relative to neutral training would lead to a decrease in fixation duration towards contamination-related images, the same mixed model MANOVA was conducted but with fixation duration for each of the four image types as the dependent variables. For the overall mixed model MANOVA, there was a significant main effect of time, $F(4,58)=8.82, p<0.001$, partial $\eta^{2}=0.38$, but no significant interaction effect, $F(4,58)=0.20, p=0.94$, partial $\eta^{2}=0.01$. Follow-up analyses of the time main effect indicated that participants in both conditions showed a significant pre- to post-training reduction in mean fixation duration towards contamination-related images, $F(1,61)=16.45$, $p<0.001$, partial $\eta^{2}=0.21$, and a significant pre- to posttraining increase in mean fixation duration towards appetitive images, $F(1,61)=27.79, p<0.001$, partial $\eta^{2}=0.31$. Again, the non-significant interaction effect indicates that conditions did not significantly differ in their pre- to posttraining changes in fixation duration towards any of the images, including contamination-related images.

\section{Condition Differences on the BATs}

\section{Number of Steps}

An independent samples t-test was used to compare conditions on the total number of steps completed on the BATs (i.e., more steps completed meaning less contaminationrelated avoidance). As predicted, the positive condition completed significantly more steps on the BAT $(M=15.90$, $S D=3.26)$ than the neutral condition $(M=13.03, S D=5.25)$, $t(62)=-2.61, p=0.01$, Cohen's $d=-0.65$.

\section{Disgust and Anxiety Ratings}

Separate independent samples t-tests were used to compare conditions on the total self-reported disgust and anxiety on the BATs. Surprisingly, conditions did not significantly differ on total self-reported disgust (positive: $M=765.48, S D=372.86$; neutral: $M=637.67, S D=324.36$ ), $t(62)=-1.47, p=0.15$, Cohen's $d=-0.37$, and anxiety (positive: $M=527.39, S D=342.12$; neutral: $M=419.76$, $S D=333.31), t(62)=-1.28, p=0.21$, Cohen's $d=-0.32$.

\section{Training-related Changes on Self-report Questionnaires}

\section{Contamination-related OCD Symptoms}

To examine whether conditions differed with regards to changes in self-reported contamination-related OCD symptoms at one-week following the training, a 2 (condition: positive vs. neutral) $\times 3$ (time: pre-training, post-training, follow-up) mixed model ANOVA was conducted, with condition as the between-subjects variable; time as the within-subjects variable; PI-WSUR scores as the dependent variable; and planned contrasts comparing pre-training with follow-up and post-training with follow-up. There was no evidence to suggest that this was the case, given the nonsignificant interaction effects for the pre-training-follow-up contrast, $F(1,60)=2.35, p=0.13$, partial $\eta^{2}=0.04$, and the post-training-follow-up contrast, $F(1,60)=1.22, p=0.27$, partial $\eta^{2}=0.02$.

\section{Contamination-related Cognitions}

The same mixed model was conducted but with CCS scores as the dependent variable. The interaction effect for the pre-training-follow-up contrast was not significant, $F(1$, $60)=3.28, p=0.08$, partial $\eta^{2}=0.05$, but it was significant for the post-training-follow-up contrast, $F(1,60)=4.05$, $p=0.05$, partial $\eta^{2}=0.06$, suggesting that conditions differed with regards to changes in self-reported contaminationrelated cognitions from immediately after the training to one-week following the training. To understand the significant interaction effect, follow-up analyses using paired samples t-tests were conducted within each condition. We found that the positive condition showed a significant decrease in their contamination-related cognitions from post-training to follow-up, $t(30)=2.35, p=0.03$, Cohen's $d=0.42$, and the neutral condition demonstrated no significant changes from post-training to follow-up, $t(30)=-0.45, p=0.66$, Cohen's $d=-0.08$.

\section{Exploratory Mediation Analysis}

A mediation (indirect effects) model using the PROCESS script for SPSS (Hayes, 2013) explored whether the significant association between the positive training and the greater number of total steps completed on the BATs was mediated by training-related changes in target bias. A change in target bias was calculated by subtracting pre-training target bias scores from post-training target bias scores. A larger change score indicated a greater change in adaptive interpretive bias of ambiguous, contamination-related scenarios. As smaller samples are prone to violating assumptions of normality required by mediation models, the sampling distribution 
Fig. 6 Mediation model with total steps completed on the BATs as the outcome variable and target bias change as the mediator. Larger change scores indicate a greater change in adaptive interpretive bias of ambiguous, contaminationrelated scenarios. Numbers represent unstandardised $\mathrm{B}$ coefficients. Condition is coded $0=$ neutral, $1=$ positive. ${ }^{*} p<.05$
Total effect model

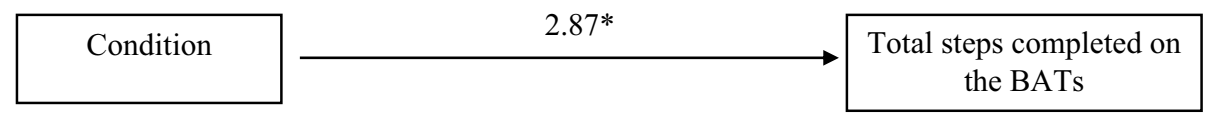

Indirect effect model

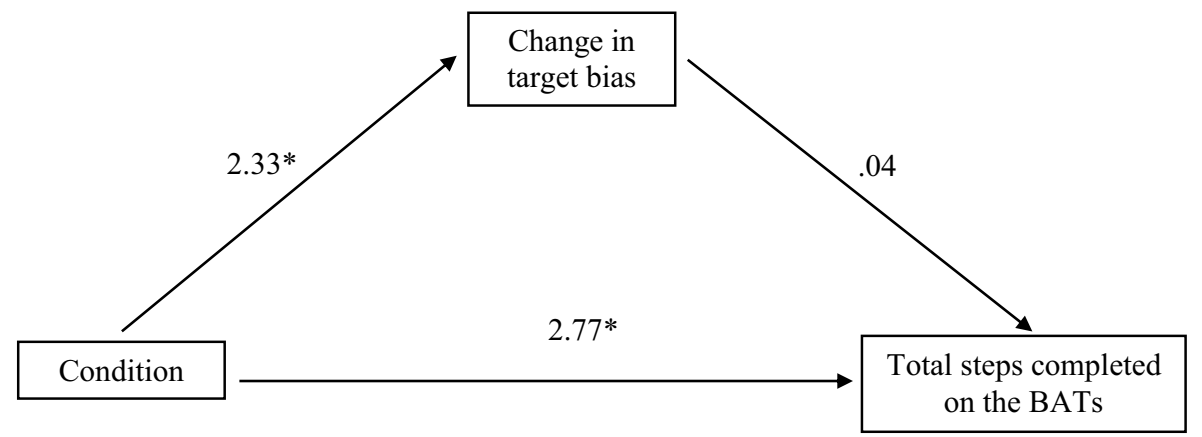

of indirect effects was bootstrapped 5,000 times to provide non-parametric estimates of these sampling distributions (see Preacher \& Hayes, 2004). In bootstrapping analysis, significant indirect effects $(p<0.05$, two-tailed) are indicated by $95 \%$ bias-corrected and accelerated confidence intervals (CI) that do not include the value of 0 .

Unstandardised indirect effect B coefficients and 95\% CI are reported in this section. The indirect effect of condition (neutral coded as 0 and positive coded as 1 ) on total steps completed on the BATs via target bias change was positive (indirect effect $\mathrm{B}$ coefficient $=0.10$ ) and not statistically different from zero (95\% CI $=-0.50$ to 0.83). See Fig. 6 .

\section{Discussion}

The current study aimed to examine the effect of CBM-I on reducing contamination-related OCD symptoms and attentional bias in a sample with elevated contamination concerns. As predicted, our positive training led to a greater increase in adaptive interpretive bias towards ambiguous contamination-related situations whereas the neutral training did not. This finding converges with those reported by Beadel et al. (2016) and Conley and Wu (2018), who were also able to train an adaptive bias in individuals with contamination concerns, despite using either a different set of training items or CBM-I methodology. Importantly, like Conley and $\mathrm{Wu}$ (2018), we showed that our positive training, relative to neutral training, was associated with less avoidance of contaminants on our behavioural approach tasks. Our results showing the cognitive changes due to CBM-I also echoes Beadel et al. (2016), such that our positive training led to a reduction in contamination-related cognitions as measured by the Contamination Cognitions Scale (Deacon
\& Olatunji, 2007). These findings appear promising for the clinical utility of CBM-I in individuals with contamination concerns.

Before this, we must address the issue that our positive training, relative to neutral training, did not lead to a greater reduction in self-reported symptoms of contaminationrelated OCD. This finding that an increase in adaptive interpretative bias without a subsequent reduction in self-reported OCD symptoms is consistent with a significant proportion of the literature on CBM-I for OCD (Beadel et al., 2014; Black \& Grisham, 2018; Stech \& Grisham, 2017; Wong et al., 2021b). A possible explanation is that one short training session might have been sufficient to reduce interpretive bias but was an inadequate dose for affecting meaningful change on questionnaires related to the individuals' primary concern, which typically frame symptoms as stable and traitlike constructs (e.g., 'I find it difficult to touch garbage or dirty things'). This dose-response hypothesis has been proposed by other CBM-I researchers (Black \& Grisham, 2018; Clerkin \& Teachman, 2011; Wong et al., 2021b), who suggest that future CBM-I studies should attempt to increase the intensity of the training (e.g., more trials per session and/or more training sessions) to elicit more robust effects.

Alternatively, the apparent dissociation between change in interpretive bias and subsequent changes in symptoms might be explained by limitations of traditional cognitivebehavioural models of OCD. That is, some have argued that the dysfunctional beliefs underlying the misappraisal of intrusions as personally significant may not be as crucial as initially thought for seeing improvements in OCD symptoms (Cougle \& Lee, 2014). Indeed, not all individuals who meet diagnostic criteria for OCD endorse obsessional beliefs (Julien et al., 2007; Taylor et al., 2006) and only some beliefs (i.e., importance of and need to control 
thoughts) predict the occurrence of intrusive thoughts and neutralising behaviours (Wahl et al., 2019). Wahl et al. (2019) also found that these beliefs also predicted depressive and anxiety symptoms that were not specific to OCD. Furthermore, we have previously used CBM-I to examine other potential causal factors in OCD and reported changes in both symptoms and behaviour (Wong \& Grisham, 2017). Specifically, we trained participants towards using a dysfunctional reasoning process that has been proposed by an alternative cognitive-behavioural model to cause OCD (i.e., inference-based approach; Aardema \& O'Connor, 2007). Relative to a control condition, participants trained in this reasoning process reported significantly more OCD symptoms and were more avoidant of potentially contaminated objects on a behavioural approach task. Combining this evidence with the current study's finding that changes in interpretive bias did not significantly mediate the relation between positive training and less avoidance of contaminants, we suggest that dysfunctional beliefs may not completely account for the development and maintenance of OCD. At the very least, this critique may only apply to the belief domains highlighted by the Obsessive Compulsive Cognitions Working Group (2001, 2005). Indeed, there is emerging evidence that negative beliefs about memory (Alcolado \& Radomsky, 2011; Radomsky et al., 2020) and about losing control (Gagné \& Radomsky, 2017, 2020) may be relevant to harm avoidance and compulsive checking in OCD, and that core beliefs about the self as corrupted may better explain symptoms of mental and contact contamination in OCD (Krause et al., 2020). As such, an area for future research in CBM-I for OCD may be to examine the effectiveness of tailoring CBM-I to address the individuals' idiosyncratic beliefs and misappraisals.

Finally, contrary to expectations, positive training was not associated with greater attentional disengagement (reduced fixation duration) for contamination-related images relative to neutral training. However, a significant increase in attentional disengagement for contamination-related images as well as a significant increase in attentional engagement for appetitive images was observed across the sample. It is possible that these shifts in attentional bias may have been due to the increase in general positive interpretive bias following the CBM-I training in both conditions. However, by this reasoning, we would have also expected an increase in attentional disengagement for general threat-related images, which was not the case. Alternatively, the repeated exposure to many contamination-related images in a sample with elevated contamination fears may have led to some habituation, thus reducing attentional engagement regardless of training condition.

\section{Limitations and Future Directions}

As outlined above, a limitation of the current study may have been that a single session of CBM-I was insufficient to change participants' self-reported symptoms of contamination-related OCD on the PI-WSUR. Similarly, the small sample size may have prevented us from finding effects on this measure due to limited power. Another limitation is that we did not measure performance on our behavioural approach tasks prior to the training (to prevent practice effects) and at the one-week followup assessment, meaning that we are currently unable to conclude whether CBM-I leads to reductions in behavioural avoidance or sustained behavioural change, respectively. Finally, the CCS may be inadequate as a measure of contaminationrelated cognitions due to its focus on the individuals' tendency to overestimate the likelihood and severity of contamination (i.e., harm). Contamination-related cognitions include content beyond harm, such as disgust, which has been argued to be a more central feature in contamination-related OCD (e.g., "I am going to feel nauseous from being in the same room as a cockroach and I will not be able to cope"; Cisler et al., 2009; Wong et al., 2021a). In addition to addressing the aforementioned limitations, future replications of the current study could adapt the appraisal rating scale described in Wong et al. (2021a) to measure disgust-related cognitions.

Overall, CBM-I researchers continue to debate the evidence regarding whether CBM-I is able to bring about meaningful and sustained changes in symptoms and behaviour (Lange et al., 2010; Macleod \& Mathews, 2012). This might be especially the case in the absence of cognitive-behavioural therapy directly targeting contamination fear and misappraisals of intrusions as personally significant. Indeed, findings from a recent study conducted in a sample of OCD patients showed that CBM-I can enhance the effectiveness of selfconducted exposure therapy by increasing its accessibility and acceptability (Amir et al., 2015). CBM-I may also be useful when given as a homework task between treatment sessions in order to reinforce the cognitive changes occurring during sessions. The ease of access to the training outside of the treatment setting and minimal clinician involvement make CBM-I an appropriate tool to provide patients with more practice with adaptive interpretations of ambiguous contamination-related scenarios. In lieu of these advantages, the potential efficacy of combining CBM-I with existing treatments for contaminationrelated OCD warrants further investigation. 


\section{Conclusion}

The current study showed that CBM-I training can help individuals with elevated contamination concerns increase their adaptive interpretations of ambiguous contamination-related scenarios, which subsequently reduced their contaminationrelated cognitions and was associated with less behavioural avoidance of contaminants. Our findings suggest the potential clinical utility of CBM-I for patients suffering from contamination-related $\mathrm{OCD}$, especially in combination with cognitive-behavioural therapy.

Funding Open Access funding enabled and organized by CAUL and its Member Institutions. This research was supported by an Australian Research Council Future Fellowship (FT140100207) awarded to the fourth author.

Data Availability Not applicable.

Code Availability Syntax for all analyses is available from the authors.

\section{Declarations}

Ethics Approval This work was approved by the Human Research Ethics Advisory Panel C of UNSW Sydney.

Consent to Participate Written informed consent was obtained from all individual participants in the study.

Consent for Publication Not applicable.

Informed Consent Informed consent was obtained from all individual participants included in the study.

\section{Conflict of Interest Not applicable.}

Experiment Participants All procedures performed in studies involving human participants were in accordance with the ethical standards of the institutional and/or national research committee and with the 1964 Helsinki declaration and its later amendments or comparable ethical standards.

Open Access This article is licensed under a Creative Commons Attribution 4.0 International License, which permits use, sharing, adaptation, distribution and reproduction in any medium or format, as long as you give appropriate credit to the original author(s) and the source, provide a link to the Creative Commons licence, and indicate if changes were made. The images or other third party material in this article are included in the article's Creative Commons licence, unless indicated otherwise in a credit line to the material. If material is not included in the article's Creative Commons licence and your intended use is not permitted by statutory regulation or exceeds the permitted use, you will need to obtain permission directly from the copyright holder. To view a copy of this licence, visit http://creativecommons.org/licenses/by/4.0/.

\section{References}

Aardema, F., \& O'Connor, K. P. (2007). The menace within: Obsessions and the self. Journal of Cognitive Psychotherapy: An International Quarterly, 21, 182-197. https://doi.org/10.1891/ 088983907781494573

Abramowitz, J. S., Nelson, C. A., Rygwall, R., \& Khandker, M. (2007). The cognitive mediation of obsessive-compulsive symptoms: A longitudinal study. Journal of Anxiety Disorders, 21, 91-104. https://doi.org/10.1016/j.janxdis.2006.05.003

Alcolado, G. M., \& Radomsky, A. S. (2011). Believe in yourself: Manipulating beliefs about memory causes checking. Behaviour Research and Therapy, 49, 42-49. https://doi.org/10.1016/j.brat. 2010.10.001

American Psychiatric Association. (2013). Diagnostic and statistical manual of mental disorders (5th ed.). Washington: American Psychiatric Publishing.

Amir, N., Bomyea, J., \& Beard, C. (2010). The effect of single-session interpretation modification on attention bias in socially anxious individuals. Journal of Anxiety Disorders, 24, 178-182. https:// doi.org/10.1016/j.janxdis.2009.10.005

Amir, N., Kuckertz, J. M., Najmi, S., \& Conley, S. L. (2015). Preliminary evidence for the enhancement of self-conducted exposures for OCD using cognitive bias modification. Cognitive Therapy and Research, 39, 424-440. https://doi.org/10.1007/ s10608-015-9675-7

Armstrong, T., Hemminger, A., \& Olatunji, B. O. (2013). Attentional bias in injection phobia: Overt components time course and relation to behavior. Behaviour Research and Therapy, 51, 266-273. https://doi.org/10.1016/j.brat.2013.02.008

Armstrong, T., Sarawgi, S., \& Olatunji, B. O. (2012). Attentional bias toward threat in contamination fear: Overt components and behavioral correlates. Journal of Abnormal Psychology, 121, 232-237. https://doi.org/10.1037/a0024453

Arntz, A., Voncken, M., \& Goosen, A. C. A. (2007). Responsibility and obsessive-compulsive disorder: An experimental test. Behaviour Research and Therapy, 45, 425-435. https://doi.org/10.1016/j. brat.2006.03.016

Beadel, J. R., Ritchey, F. C., \& Teachman, B. A. (2016). Role of fear domain match and baseline bias in interpretation training for contamination fear. Journal of Experimental Psychopathology, 7, 49-71. https://doi.org/10.5127/jep.045414

Beadel, J. R., Smyth, F. L., \& Teachman, B. A. (2014). Change processes during cognitive bias modification for obsessive-compulsive beliefs. Cognitive Therapy and Research, 38, 103-119. https://doi. org/10.1007/s10608-013-9576-6

Black, M. J., \& Grisham, J. R. (2018). A pilot study of interpretive cognitive bias modification for OCD: Targeting memory uncertainty and perfectionism biases. Journal of Experimental Psychopathology, 9, 2043808718778969. https://doi.org/10.1177/ 2043808718778969

Burns, G. L., Keortge, S., Formea, G. M., \& Sternberger, L. G. (1996). Revision of the Padua Inventory of obsessive compulsive disorder symptoms: Distinctions between worry obsessions and compulsions. Behaviour Research and Therapy, 34, 163-173. https://doi. org/10.1016/0005-7967(95)00035-6

Cisler, J. M., Olatunji, B. O., \& Lohr, J. M. (2009). Disgust fear and the anxiety disorders: A critical review. Clinical Psychology Review, 29, 34-46. https://doi.org/10.1016/j.cpr.2008.09.007

Clerkin, E. M., Magee, J. C., \& Parsons, E. M. (2014). Evaluating change in beliefs about the importance/control of thoughts as a mediator of CBM-I and responses to an ICT stressor. Journal of Obsessive-Compulsive and Related Disorders, 3, 311-318. https:// doi.org/10.1016/j.jocrd.2014.07.002 
Clerkin, E. M., \& Teachman, B. A. (2011). Training interpretation biases among individuals with symptoms of obsessive compulsive disorder. Journal of Behavior Therapy and Experimental Psychiatry, 42, 337-343. https://doi.org/10.1016/j.jbtep.2011.01.003

Conley, S. L., \& Wu, K. D. (2018). Experimental modification of dysfunctional interpretations in individuals with contamination concerns. Journal of Behavior Therapy and Experimental Psychiatry, 59, 56-64. https://doi.org/10.1016/j.jbtep.2017.11.005

Coughtrey, A. E., Shafran, R., Knibbs, D., \& Rachman, S. (2012). Mental contamination in obsessive-compulsive disorder. Journal of Obsessive-Compulsive and Related Disorders, 20, 221-231. https://doi.org/10.1016/j.cbpra.2012.07.002

Cougle, J., \& Lee, H. J. (2014). Pathological and non-pathological features of obsessive-compulsive disorder: Revisiting basic assumptions of cognitive models. Journal of Obsessive-Compulsive and Related Disorders, 3, 12-20. https://doi.org/10.1016/j.jocrd.2013. 11.002

Cougle, J., Wolitzky-taylor, K., Lee, H. J., \& Telch, M. J. (2007). Mechanisms of change in ERP treatment of compulsive hand washing: Does primary threat make a difference? Behaviour Research and Therapy, 45, 1449-1459. https://doi.org/10.1016/j. brat.2006.12.001

Deacon, B. J., \& Olatunji, B. O. (2007). Specificity of disgust sensitivity in the prediction of behavioral avoidance in contamination fear. Behaviour Research and Therapy, 45, 2110-2120. https://doi.org/ 10.1016/j.brat.2007.03.008

Foa, E. B., Huppert, J. D., Leiberg, S., Langner, R., Kichic, R., Hajcak, G., \& Salkovskis, P. M. (2002). The Obsessive-Complusive Inventory: Development and validation of a short version. Psychological Assessment, 14, 485-495. https://doi.org/10.1037//1040-3590. 14.4.485

Foa, E. B., Ilai, D., McCarthy, P. R., Shoyer, B., \& Murdock, T. (1993). Information processing in obsessive-compulsive disorder. Cognitive Therapy and Research, 17, 173-189.

Frost, R. O., \& Steketee, G. (1997). Perfectionism in obsessive-compulsive disorder patients. Behaviour Research and Therapy, 35, 291-296. https://doi.org/10.1016/S0005-7967(96)00108-8

Gagné, J. P., \& Radomsky, A. S. (2017). Manipulating beliefs about losing control causes checking behaviour. Journal of ObsessiveCompulsive and Related Disorders, 15, 34-42. https://doi.org/ 10.1016/j.jocrd.2017.08.013

Gagné, J. P., \& Radomsky, A. S. (2020). Beliefs about losing control, obsessions, and caution: An experimental investigation. Behaviour Research and Therapy, 126, 103574. https://doi.org/ 10.1016/j.brat.2020.103574

Goodman, W. K., Price, L. H., Rasmussen, S. A., Mazure, C., Fleischmann, R. L., Hill, C., Heninger, G. R., \& Charney, D. S. (1989). Yale-Brown Obsessive Compulsive Scale (Y-BOCS). Archives of General Psychiatry, 46, 1006-1011.

Grisham, J. R., Becker, L., Williams, A. D., Whitton, A. E., \& Makkar, S. R. (2014). Using cognitive bias modification to deflate responsibility in compulsive checkers. Cognitive Therapy and Research, 38, 505-517. https://doi.org/10.1007/ s10608-014-9621-0

Hayes, A. (2013). Introduction to mediation moderation and conditional process analysis: A regression-based approach. New York: The Guilford Press.

Julien, D., O'Connor, K. P., \& Aardema, F. (2007). Intrusive thoughts, obsessions, and appraisals in obsessive-compulsive disorder: A critical review. Clinical Psychology Review, 27, 366-383. https:// doi.org/10.1016/j.cpr.2006.12.004

Krause, S., Wong, S. F., Giraldo-O'Meara, M., Aardema, F., \& Radomsky, A. S. (2020). It's not so much about what you touch: Mental contamination mediates the relationship between feared self-perceptions and contact contamination. Journal of Obsessive-Compulsive and Related Disorders, 25, 100507. https://doi.org/10.1016/j.jocrd.2020.100507
Lang, P. J., Bradley, M. M., \& Cuthbert, B. N. (2005). International affective picture system (IAPS): Affective ratings of pictures and instruction manual. University of Florida.

Lange, W. G., Salemink, E., Windey, I., Keijsers, G. P. J., Krans, J., Becker, E. S., \& Rinck, M. (2010). Does modified interpretation bias influence automatic avoidance behaviour? Applied Cognitive Psychology, 24, 326-337. https://doi.org/10.1002/acp.1679

Macleod, C., \& Mathews, A. (2012). Cognitive bias modification approaches to anxiety. Annual Review of Clinical Psychology, 8, 189-217. https://doi.org/10.1146/annurev-clinpsy-032511-143052

Maltby, N., \& Tolin, D. F. (2003). Overview of treatments for obsessivecompulsive disorder: Conceptualization, theory, and practice. Brief Treatment and Crisis Intervention, 3, 127-144.

Mathews, A., \& Mackintosh, B. (2000). Induced emotional interpretation bias and anxiety. Journal of Abnormal Psychology, 109, 602-615. https://doi.org/10.1037//0021-843X.109.4.602

Najmi, S., Tobin, A. C., \& Amir, N. (2012). Psychometric properties of a behavioral test of contamination-related obsessive-compulsive symptoms. Cognitive Therapy and Research, 36, 228-233. https:// doi.org/10.1007/s10608-010-9332-0

Obsessive Compulsive Cognitions Working Group. (2001). Development and initial validation of the Obsessive Beliefs Questionnaire and the Interpretation of Intrusions Inventory. Behaviour Research and Therapy, 39, 987-1006. https://doi.org/10.1016/ S0005-7967(00)00085-1

Obsessive Compulsive Cognitions Working Group. (2005). Psychometric validation of the Obsessive Belief Questionnaire and Interpretation of Intrusions Inventory - Part 2: Factor analyses and testing of a brief version. Behaviour Research and Therapy, 43, 1527-1542. https://doi.org/10.1016/j.brat.2004.07.010

Preacher, K. J., \& Hayes, A. (2004). SPSS and SAS procedures for estimating indirect effects in simple mediation models. Behavior Research Methods, Instruments, and Computers, 36, 717-731. https://doi.org/10.3758/BF03206553

Purdon, C., Rowa, K., \& Antony, M. M. (2005). Thought suppression and its effects on thought frequency, appraisal, and mood state in individuals with obsessive-compulsive disorder. Behaviour Research and Therapy, 43, 93-108. https://doi.org/10.1016/j. brat.2003.11.007

Rachman, S. (1997). A cognitive theory of obsessions. Behaviour Research and Therapy, 35, 793-802. https://doi.org/10.1016/ S0005-7967(97)00040-5

Rachman, S. (1998). A cognitive theory of obsessions: Elaborations. Behaviour Research and Therapy, 36, 385-401. https://doi.org/ 10.1016/S0005-7967(97)10041-9

Rachman, S., \& de Silva, P. (1978). Abnormal and normal obsessions. Behaviour Research and Therapy, 16, 233-248. https://doi.org/ 10.1016/0005-7967(78)90022-0

Radomsky, A. S., Alcolado, G. M., Abramowitz, J. S., Alonso, P., Belloch, A., Bouvard, M., Clark, D. A., Coles, M. E., Doron, G., FernandezAlvarez, H., Garcia-Soriano, G., Ghisi, M., Gomez, B., Inozu, M., Moulding, R., Shams, G., Sica, C., Simos, G., \& Wong, W. (2014). Part 1 You can run but you can't hide: Intrusive thoughts on 6 continents. Journal of Obsessive-Compulsive and Related Disorders, 3, 269-279. https://doi.org/10.1016/j.jocrd.2013.09.002

Radomsky, A. S., Wong, S. F., Giraldo-O'Meara, M., Dugas, M. J., Gelfand, L. A., Myhr, G., Schell, S. E., Senn, J. M., Shafran, R., \& Whittal, M. L. (2020). When it's at: An examination of when cognitive change occurs during cognitive therapy for compulsive checking in obsessive-compulsive disorder. Journal of Behavior Therapy and Experimental Psychiatry, 67, 101442. https://doi. org/10.1016/j.jbtep.2018.12.003

Reeves, J., Reynolds, S., Coker, S., \& Wilson, C. (2010). An experimental manipulation of responsibility in children: A test of the inflated responsibility model of obsessive-compulsive disorder. 
Journal of Behavior Therapy and Experimental Psychiatry, 41, 228-233. https://doi.org/10.1016/j.jbtep.2010.01.007

Salkovskis, P. M. (1985). Obsessional-compulsive problems: A cognitivebehavioural analysis. Behaviour Research and Therapy, 23, 571-583. https://doi.org/10.1016/0005-7967(85)90105-6

Salkovskis, P. M. (1989). Cognitive-behavioural factors and the persistence of intrusive thoughts in obsessional problems. Behaviour Research and Therapy, 27, 677-682. https://doi.org/10.1016/ 0005-7967(89)90152-6

Salkovskis, P. M., Shafran, R., Rachman, S., \& Freeston, M. H. (1999). Multiple pathways to inflated responsibility beliefs in obsessional problems: Possible origins and implications for therapy and research. Behaviour Research and Therapy, 37, 1055-1072. https://doi.org/10.1016/S0005-7967(99)00063-7

Stech, E. P., \& Grisham, J. R. (2017). Modifying obsessive-compulsive beliefs about controlling one's thoughts. Journal of Psychopathology and Behavioral Assessment, 39, 534-545. https://doi.org/10. 1007/s10862-017-9603-0

Tata, P., Leibowitz, J. A., Prunty, M. J., Cameron, M., \& Pickering, A. D. (1996). Attentional bias in obsessional compulsive disorder. Behaviour Research and Therapy, 34, 53-60. https://doi.org/10. 1016/0005-7967(95)00041-U

Taylor, S., Abramowitz, J. S., McKay, D., Calamari, J. E., Sookman, D., Kyrios, M., Wilhelm, S., \& Carmin, C. (2006). Do dysfunctional beliefs play a role in all types of obsessive-compulsive disorder? Journal of Anxiety Disorders, 20, 85-97. https://doi.org/ 10.1016/j.janxdis.2004.11.005

Tolin, D. F., Abramowitz, J. S., Brigidi, B. D., \& Foa, E. B. (2003). Intolerance of uncertainty in obsessive-compulsive disorder. Journal of Anxiety Disorders, 17, 233-242. https://doi.org/10.1016/ S0887-6185(02)00182-2

Tümkaya, S., Karadağ, F., \& Oğuzhanoğlu, N. K. (2015). Relationship between obsessive beliefs and symptoms in patients with obsessive compulsive disorder. Nöro Psikiyatri Arşivi, 52, 54-58. https://doi.org/10.5152/npa.2015.7015

Wahl, K., Hofer, P. D., Meyer, A. H., \& Lieb, K. (2019). Prior beliefs about the importance and control of thoughts are predictive but not specific to subsequent intrusvie unwated thoughts and neutralizing behaviors. Cognitive Therapy and Research, 44, 360-375. https://doi.org/10.1007/s10608-019-10046-7

White, L. K., Suway, J. G., Pine, D. S., Bar-Haim, Y., \& Fox, N. A. (2011). Cascading effects: The influence of attention bias to threat on the interpretation of ambiguous information. Behaviour Research and Therapy, 49, 244-251. https://doi.org/10.1016/j. brat.2011.01.004

Whitton, A. E., Grisham, J. R., Henry, J. D., \& Palada, H. D. (2013). Interpretive bias modification for disgust. Journal of Experimental Psychopathology, 4, 341-359. https://doi.org/10.5127/jep.030812

Williams, A. D., \& Grisham, J. R. (2013). Cognitive bias modification (CBM) of obsessive-compulsive beliefs. BMC Psychiatry, 13, 256-264. https://doi.org/10.1186/1471-244X-13-256

Williams, J. M. G., Watts, F. N., MacLeod, C., \& Mathews, A. (1997). Cognitive psychology and emotional disorders (2nd ed.). Hoboken: John Wiley \& Sons.

Wong, S. F., \& Grisham, J. R. (2017). Causal role for inverse reasoning on obsessive-compulsive symptoms: Preliminary evidence from a cognitive bias modification for interpretation bias study. Journal of Behavior Therapy and Experimental Psychiatry, 57, 143-155. https://doi.org/10.1016/j.jbtep.2017.06.001

Wong, S. F., Krause, S., Marishel, D., \& Grisham, J. R. (2021a). Reappraisal of disgust: Self-report and behavioural assessment of individuals with moderate to high contamination fears. Journal of Anxiety Disorders, 78, 102346. https://doi.org/10.1016/j.janxdis. 2020.102346

Wong, S. F., Lim, V., Black, M. J., \& Grisham, J. R. (2021b). The impact of modifying obsessive-compulsive beliefs about perfectionism. Journal of Behavior Therapy and Experimental Psychiatry, 73, 101675. https://doi.org/10.1016/j.jbtep.2021.101675

Publisher's Note Springer Nature remains neutral with regard to jurisdictional claims in published maps and institutional affiliations. 